\title{
Effect of different polyethers on surface and thermal properties of poly(urethane-siloxane) copolymers modified with side-chain siloxane
}

\author{
Eukasz Byczyński
}

Received: 6 August 2012/Accepted: 14 December 2012/Published online: 16 January 2013

(c) The Author(s) 2013. This article is published with open access at Springerlink.com

\begin{abstract}
Poly(urethane-dimethylsiloxane) (PU-PDMS) copolymers with $4,4^{\prime}$-methylenebis(cyclohexyl isocyanate), different polyethers i.e., poly(oxytetramethylene)diol, poly (ethylene glycol), poly(propylene glycol), and $\alpha, \omega$-dihydroxy terminated polydimethylsiloxane extended with 1,4butanediol in two-step solution polymerization were obtained. The PU-PDMS were modified using $1.25 \mathrm{~mol} \%$ of polydimethylsiloxane which was incorporated into main polyurethane backbone as a side chain. The structure of the synthesized PU-PDMS was confirmed by FTIR as well as ${ }^{1} \mathrm{H}$ and ${ }^{13} \mathrm{C}-\mathrm{NMR}$ spectroscopy. The effect of different soft segments on free surface energy (FSE) components and thermal stability of poly(urethane-siloxane) copolymers was investigated. The activation energy of the thermal degradation of PU-PDMS using isoconversional methods (OzawaFlynn-Wall and Friedman) was calculated. It was concluded that molecular mass, thermal stability, and FSE of PU-PDMS copolymers depend on polyol used. The apparent activation energy at first step of degradation in nitrogen generally increases with the extent of conversion which may result from complex mechanism related to formation of decomposition products. Hydrophobic character of side-chain siloxane on surface properties of the PU-PDMS coatings was confirmed. The obtained coatings are generally soft with the relative hardness in the range of $0.120-0.027$.
\end{abstract}

Keywords Polyurethane - Siloxane - Side chain · Surface free energy $\cdot$ Thermal stability $\cdot$ Kinetics

\footnotetext{
Ł. Byczyński $(\square)$

Department of Polymer Science, Faculty of Chemistry, Rzeszów University of Technology, Al. Powstańców Warszawy 6,

35-959 Rzeszów, Poland

e-mail: lbyczynski@prz.edu.pl
}

\section{Introduction}

Poly(urethane-siloxane) copolymers (PU-Si) are a class of hybrid polymers which are situated on a boundary between organic and inorganic materials. They consist of organic segments derived from polyurethane and inorganic siloxane structures. PU-Si materials combine advantages of both comonomers used, i.e., good tensile strength and abrasion resistance which are specific for polyurethane, with low free surface energy (FSE) and glass transition, great elasticity (especially at low temperature) as well as good thermal, chemical, and biological stability which are contributed to the system by polysiloxanes. Owing to their properties, PU-Si are widely used as protection coatings, medical implants, or even liquid bandage [1-5].

The modification of polyurethanes by siloxane is mostly achieved by introduction of usually linear polydimethylsiloxane into PU backbone as a part of soft segments [4, 6-8]. However, the investigations on polyurethanes with other polysiloxane structure have been recently developed [9-12].

Pergal et al. [9] performed studies on synthesis of novel polyurethane copolymers derived from 4,4-methylenediphenyl diisocyanate, 1,4-butanediol, and $\alpha, \omega$-dihydroxy-[poly (caprolactone)-poly(dimethylsiloxane)-poly(caprolactone)].

It was found from DSC and WAXS results that siloxane segments crystallized, and, additionally, SEM images confirmed the presence of a spherulitic morphology. The synthesis of moisture cured PU with the use of $\alpha, \omega$-bis (3-aminopropyldiethoxylsilane) poly(trifluoropropylmethyl)siloxane (APFS) was performed by Shi and Wang [10]. They found that the extent of microphase separation of the samples would increase with the increase in APFS content, and result in the decrease in the tensile strength and the thermal stability. In other paper waterborne PU were synthesized 
with $\alpha, \omega$-bis(3-hydroxypropyl)-functionalized poly\{dimethylsiloxane-comethyl [3-(2-acetylacetoxy)] propylsiloxane [11]. This siloxane was used as self-cross-linking agent in reaction with dihydrazide for PU at ambient temperature. The cross-linked PU-Si revealed lowered water absorption. Wang et al. [13] synthesized PU-PDMS copolymers by modification of PU surface via grafting through the introduction of vinyl and $\mathrm{Si}-\mathrm{H}$ groups onto the PU surface to improve the adhesion of PU to silicone rubber.

There are relatively little papers concerning studies on properties of PU-Si which are obtained with polysiloxane containing two reactive groups at one side of a chain. Owing to its structure, this siloxane was inbuilt as a pendant chain into main polyurethane backbone [14-17].

$\mathrm{Li}$ et al. [14] investigated the influence of siloxane length on the properties of PU-Si elastomers obtained both from main-chain as well as side-chain siloxanes. The molecular masses of the poly(urethane-siloxane) depended on the types of siloxanes used. Side-chain siloxanes yielded a higher molecular mass of PU copolymers than the mainchain siloxanes. The incorporation of main-chain siloxanes into polyurethane improved the elongation at break greatly, whereas side-chain siloxanes enhanced the ultimate tensile stress. The PU-Si anionomers containing pendant siloxane was studied as well. This kind of PU anionomers, which were cross-linked with $\mathrm{N}$-methylmonoethanolamine, compared to main-chain siloxane PU films, showed larger advancing contact angles but lower gloss and poorer tensile strength at the same amount of PDMS and similar molecular mass [15]. Chen et al. [16] compared the properties of PU-Si anionomers in which polydimethylsiloxane was introduced into the PU chain either based on random distribution or through the block segment arrangement. The contact angle of the PU-Si film increased rapidly and reached a maximum at a siloxane amount of about $7 \%$. Moreover, in the block poly(urethane-siloxane) anionomers, siloxanes moved to the surface much more easily than in the case of the random PU-Si, which as evidenced by the scanning electron microscope and energy dispersive spectroscopy (SEM-EDS) studies. However, there is still little known about thermal properties of this kind of PU-PDMS.

The aim of these investigations was to study the influence of different polyols (poly(oxytetramethylene)diol, poly(ethylene glycol), poly(propylene glycol), and $\alpha, \omega$-dihydroxy terminated polydimethylsiloxane) on surface and thermal properties of poly(urethane-siloxane) copolymers obtained with 4,4'-methylenebis(cyclohexyl isocyanate) and 1,4-butanediol which were modified with polydimethylsiloxane. This PDMS contained two hydroxyl groups located at one side of siloxane chain. Owing to its structure, the polydimethylsiloxane was introduced as side chain into main polyurethane backbone.

\section{Experimental}

\section{Materials}

4,4'-Methylenebis(cyclohexyl isocyanate) ( $\mathrm{H}_{12} \mathrm{MDI}, 90 \%$ mixture of isomers) and dibutyltin dilaurate (DBTDL) from Aldrich were used without further purification. Poly(oxytetramethylene)diol (PTMO, $M_{\mathrm{n}}=1,000$ and 2,000), poly(ethylene glycol) (PEG $\left.M_{\mathrm{n}}=1,000\right)$, and poly(propylene glycol) (PPG, $\left.M_{\mathrm{n}}=1,000\right)$ were purchased from Aldrich. Two kinds of polysiloxanes $\alpha, \omega$-dihydroxy terminated polydimethylsiloxane (L-PDMS, $M_{\mathrm{n}} \approx 1,000$ ) and side-chain siloxane (S-PDMS, $\left.M_{\mathrm{n}} \approx 2736\right)$ which structures are presented in Table 1 were kindly donated by Shin-Etsu (Japan). All the polyols were dried in a vacuum oven at $105{ }^{\circ} \mathrm{C}$ before use. 1,4-butanediol (BD, Aldrich) used as a chain extender was dried over $4 \AA$ molecular sieves. 2-butanone (MEK, POCh, Poland) were distilled and dried over $4 \AA$ molecular sieves as well.

\section{Synthesis of polyurethane}

The polyurethane (T1) was obtained in two-step solvent synthesis. At the 1 st stage, $\mathrm{H}_{12} \mathrm{MDI}$ was placed in $100-\mathrm{ml}$ three-necked flask equipped with a mechanical stirrer, thermometer, reflux condenser, and nitrogen inlet and diluted in MEK. Then, PTMO $\left(M_{\mathrm{n}}=1,000\right)$ diluted in MEK was added drop by drop to the flask. After that, DBTDL as catalyst was added. The reaction was allowed to proceed at $60{ }^{\circ} \mathrm{C}$ till content of unreacted isocyanate groups reached half of initial value (ca. $30 \mathrm{~min}$ ). Then, at the 2 nd step, $\mathrm{BD}$ was added and the temperature was raised to $60{ }^{\circ} \mathrm{C}$. The mixture was maintained at this temperature for about $2 \mathrm{~h}$ till the $-\mathrm{NCO}$ content reached $0 \%$. The conversion of $-\mathrm{NCO}$ at each step was determined by a standard dibutylamine back titration method [18]. The molar ratio of $\mathrm{H}_{12} \mathrm{MDI}$ PTMO:BD was $2: 1: 1$.

Table 1 Structure of polydimethylsiloxane compounds

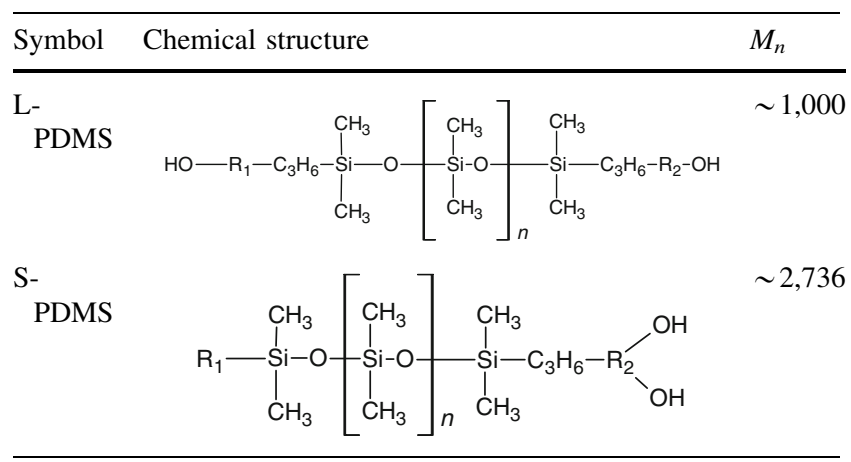


General procedure of synthesis of poly(urethanesiloxane) copolymers

All the poly(urethane-siloxane) copolymers contain $1.25 \mathrm{~mol} \%$ of S-PDMS. The molar ratio of $\mathrm{H}_{12} \mathrm{MDI}$ :polyol:S-PDMS:BD $=2: 0.95: 0.05: 1$. The PU-PDMS were obtained in similar procedure as described for polyurethane. At the 1st stage, $\mathrm{H}_{12}$ MDI was placed in $100-\mathrm{ml}$ three-necked flask equipped with a mechanical stirrer, thermometer, reflux condenser, and nitrogen inlet and diluted in MEK. Then, mixture of different polyether (PTMO, PEG, PPG or L-PDMS) and S-PDMS diluted in MEK were added drop by drop to the flask and DBTDL was added. The reaction was allowed to proceed at $60{ }^{\circ} \mathrm{C}$ till content of free isocyanate groups reached half of initial value (ca. $1 \mathrm{~h}$ ). Then at the chain extension step BD was added, and the temperature was raised to $60{ }^{\circ} \mathrm{C}$. The mixture was maintained at this temperature for about $2 \mathrm{~h}$ to reach total $-\mathrm{NCO}$ conversion.

Using above described procedures, 6 samples of copolymers were obtained with the solid content ca. $30 \mathrm{wt} \%$. The structure of synthesized PU-PDMS was presented in Fig. 1 and the detailed composition of PU-PDMS copolymers-in Table 2 . The polymer coatings for further investigations were prepared by pouring the solution of the polymers on the apolar surface of poly(tetrafluoroethylene) (PTFE), followed by draying in an vacuum oven at $85{ }^{\circ} \mathrm{C}$ for $12 \mathrm{~h}$. Then, the samples were conditioned at room temperature for 10 days before testing.

\section{Characterization}

\section{IR spectroscopy}

IR spectra were recorded with the spectrophotometer Nicolet 6700 in air, within the range of $4,000-500 \mathrm{~cm}^{-1}$, with the use of ATR technique. The obtained spectra were presented as the relation of transmittance (\%) versus wave number $\bar{v}\left(\mathrm{~cm}^{-1}\right)$.

\section{NMR spectroscopy}

${ }^{1} \mathrm{H}$ NMR and ${ }^{13} \mathrm{C}$ NMR spectra of the polymers were recorded with the use of the spectrometer FT NMR Bruker

Fig. 1 Structure of synthesized PU-PDMS copolymers

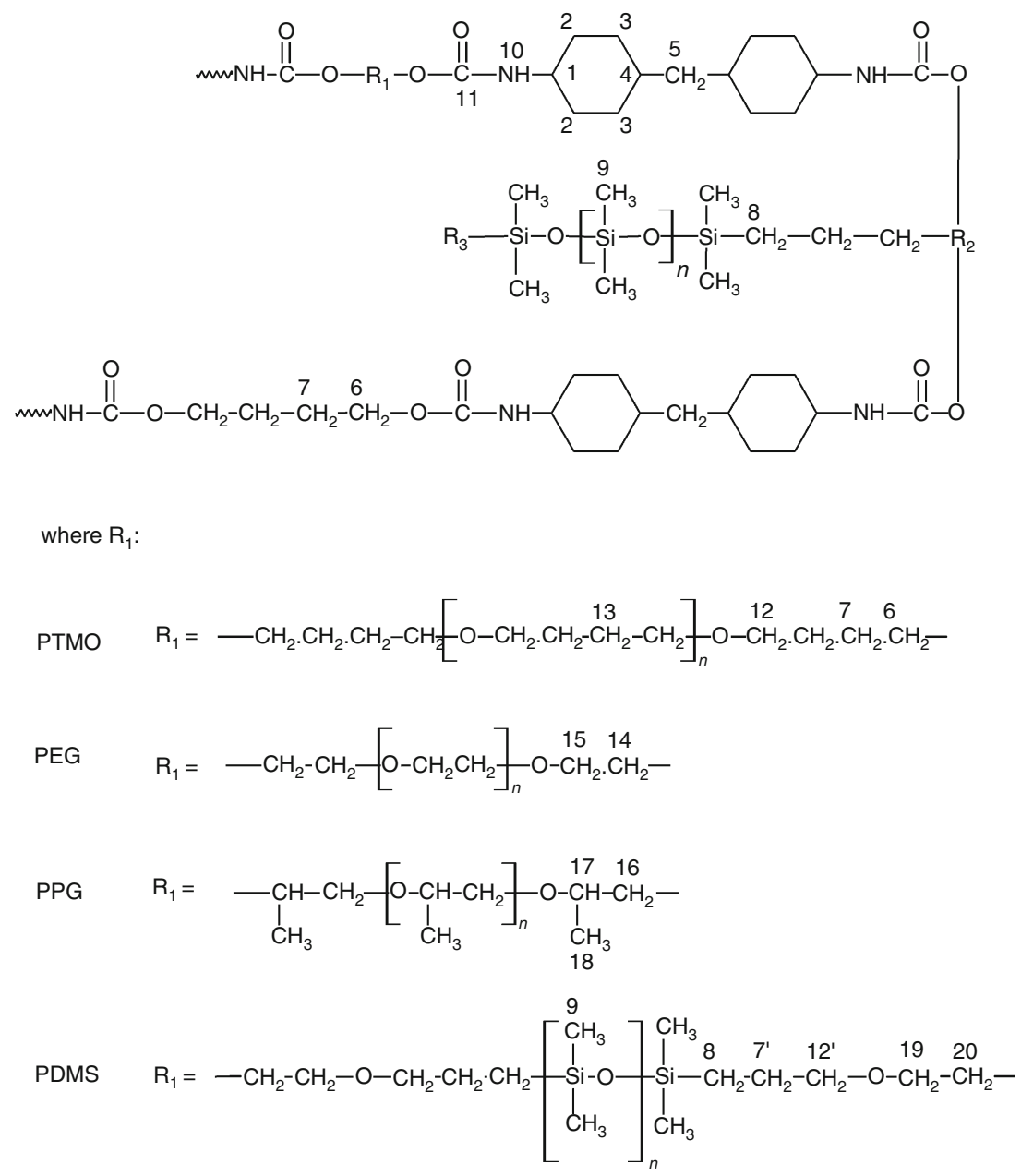


Table 2 Composition of PU-PDMS copolymers

\begin{tabular}{|c|c|c|c|c|c|c|c|c|c|c|}
\hline \multirow[t]{2}{*}{ Sample } & \multicolumn{8}{|c|}{ Amount of monomers/mol } & \multirow[t]{2}{*}{$\mathrm{HS} / \mathrm{wt} \%^{\mathrm{a}}$} & \multirow[t]{2}{*}{$\overline{\mathrm{SS}} \mathrm{wt} \%^{\mathrm{b}}$} \\
\hline & $\mathrm{H}_{12} \mathrm{MDI}$ & РТMO 1000 & PTMO 2000 & PEG 1000 & PPG 1000 & L-PDMS 1000 & S-PDMS & $\mathrm{BD}$ & & \\
\hline $\mathrm{T} 1$ & 2 & 1 & & & & & & 1 & 38.1 & 61.9 \\
\hline $\mathrm{T} 1 \mathrm{~S}$ & & 0.95 & & & & & 0.05 & & 44.2 & 55.8 \\
\hline $\mathrm{T} 2 \mathrm{~S}$ & & & 0.95 & & & & & & 28.3 & 71.7 \\
\hline E1S & & & & 0.95 & & & & & 44.2 & 55.8 \\
\hline P1S & & & & & 0.95 & & & & & \\
\hline S1S & & & & & & 0.95 & & & & \\
\hline
\end{tabular}

${ }^{\mathrm{a}}$ Hard segment content $(\mathrm{wt} \%)=(\mathrm{H} 12 \mathrm{MDI}+\mathrm{BD}+\mathrm{S}-\mathrm{PDMS}) \times 100 \% /(\mathrm{H} 12 \mathrm{MDI}+\mathrm{BD}+\mathrm{S}-\mathrm{PDMS}+$ polyol $)$

b Soft segment content $(\mathrm{wt} \%)=100 \%$ - hard segment content

Avance 500 ${ }^{\mathrm{II}}$. The samples of PU-PDMS were dissolved in $\mathrm{CDCl}_{3}$ and the solutions with the concentration of about $0.2 \mathrm{~g} \mathrm{dm}^{-3}$ were prepared. TMS was used as a standard.

\section{Gel permeation chromatography (GPC)}

GPC chromatograms were performed using a Waters Alliance 2695 GPC system equipped with a Waters 2414 RI detector and a set of three serially connected $7.8 \times 300 \mathrm{~mm}$ columns (Waters Styragel HR1, HR2 and HR4). The pore sizes of columns are as follows: 10, 100, and 1,000 ̊. Molecular masses and polydispersity indices were calculated on the basis of point to point calibration curve of polystyrene Shodex standards in the range from $1.31 \times 10^{3}$ to $3.64 \times 10^{6} \mathrm{Da}$. THF was used as an eluent in a $0.6 \mathrm{~mL} \mathrm{~min} \mathrm{~m}^{-1}$ isocratic flow. Columns were maintained at $35{ }^{\circ} \mathrm{C}$. All samples were prepared as ca. $10 \mathrm{wt} \%$ solutions in tetrahydrofuran.

\section{Thermogravimetric analysis (TG)}

Thermogravimetric analysis was performed using a Mettler Toledo TG/DSC1. The TG experiments have been carried out in nitrogen from 25 to $500{ }^{\circ} \mathrm{C}$ with varying heating rates $2.5 ; 5 ; 10 ; 20{ }^{\circ} \mathrm{C} \mathrm{min}^{-1}$ as well as in air gas flow from 25 to $600{ }^{\circ} \mathrm{C}$ with $10{ }^{\circ} \mathrm{C} \mathrm{min}{ }^{-1}$ heating rate. The measurement conditions were as follows: sample mass $\sim 5 \mathrm{mg}$, gas flow $-50 \mathrm{~cm}^{3} \mathrm{~min}^{-1}$, alumina pan. The degradation kinetics parameters in nitrogen were evaluated with the use of the Netzsch Thermokinetic Program.

\section{Surface roughness measurements}

The surface roughness of the coatings were investigated by means of profile method with the use a Mar Surf PS1 apparatus (Mahr GmbH, Germany), according to PN-EN ISO 12085:2009 standard. Measurements were performed at temperature $21 \pm 0.1{ }^{\circ} \mathrm{C}, L_{\mathrm{T}}=5600 \mathrm{~mm}$, and $L_{\mathrm{C}}=$ $0.800 \times 5$. The values of arithmetic mean deviation of the assessed profile $\left(\mathrm{R}_{\mathrm{a}}\right)$ and max. height of the profile within a sampling length $\left(R_{\mathrm{z}}\right)$ were used to characterize the coating roughness.

\section{Contact angles measurement}

The contact angles $\Theta$ were measured using the method suggested by Zisman [19] i.e., by means of optical goniometer (Cobrabid Optica-Warsaw) with a digital camera installed instead in axial extension of its lens. The standard liquid drops of water, formamide, or diiodomethane with the constant volume $(5 \mu \mathrm{L})$ were applied on the surfaces of studied samples with the use of a special micropipette. The measurements were taken in temperature at $21 \pm 2{ }^{\circ} \mathrm{C}$. The values of contact angles were found from the geometric analysis of pictures taken for liquid drops, using the original software Kropelka. The result of contact angle for one standard liquid was average of 11 measurements after rejecting of extreme values.

\section{Method for determination of the FSE components for solids}

Physical parameters of the FSE for solids $\gamma_{S}$ were found in the present study on the basis of the van Oss-Good (vOG) [20, 21] and Owens-Wendt (OW) [22] models.

The van Oss-Good model assumes that the FSE $\gamma_{\mathrm{S}}$ can be presented as a sum of two components [20, 21]:

$\gamma_{\mathrm{S}}=\gamma_{\mathrm{S}}^{\mathrm{LW}}+\gamma_{\mathrm{S}}^{\mathrm{AB}}$

where $\gamma_{\mathrm{S}}^{\mathrm{LW}}$-FSE connected with long-range interactions (dispersion, polar and induction interactions), $\gamma_{\mathrm{S}}^{\mathrm{AB}}-\mathrm{FSE}$ connected with acid-base interactions as results from the Lewis theory which is composed of $\gamma_{S}^{+}$- component related to Lewis acid and $\gamma_{\mathrm{S}}^{-}$-component related to Lewis base.

Taking into account the FSE components in the meaning as it was described above. van Oss and Good proposed an equation that establishes the relation between the FSE 
parameters of the standard liquids (L) and of the investigated surface of solid (S):

$$
\begin{aligned}
& \left(\gamma_{\mathrm{S}}^{\mathrm{LW}} \gamma_{\mathrm{L}, i}^{\mathrm{LW}}\right)^{0.5}+\left(\gamma_{\mathrm{S}}^{+}+\gamma_{\mathrm{L}, \mathrm{i}}^{-}\right)^{0.5}+\left(\gamma_{\mathrm{S}}^{-}+\gamma_{\mathrm{L}, \mathrm{i}}^{+}\right)^{0.5} \\
& =\gamma_{\mathrm{L}, \mathrm{i}} \frac{\left(1+\cos \Theta_{\mathrm{i}}\right)}{2}
\end{aligned}
$$

where $\Theta$ - the experimentally found contact angle between a liquid drop and a solid surface under investigation, $i$-concerns the used standard liquid.

The Owens-Wendt model assumes that the FSE $\gamma_{s}$ of the solid state may be presented as a sum of two components [22]:

$\gamma_{\mathrm{S}}=\gamma_{\mathrm{S}}^{\mathrm{d}}+\gamma_{\mathrm{S}}^{\mathrm{p}}$

where $\gamma_{S}^{\mathrm{d}}-$ FSE connected with dispersion interactions (dispersion, polar, and induction interactions), $\gamma_{S}^{\mathrm{p}}-\mathrm{FSE}$ connected with polar interactions.

Using the above described SFE components, Owens and Wendt proposed an equation that establishes the relation between the surface free energy parameters of the standard liquids (L) and of the investigated surface of solid (S):

$\gamma_{\mathrm{L}} \frac{1+\cos \Theta}{2}=\left(\gamma_{\mathrm{S}}^{\mathrm{d}} \gamma_{\mathrm{L}}^{\mathrm{d}}\right)^{0.5}+\left(\gamma_{\mathrm{S}}^{\mathrm{p}} \gamma_{\mathrm{L}}^{\mathrm{p}}\right)^{0.5}$

where $\Theta$ - the experimentally found contact angle between a liquid drop and a solid surface under investigation.

In order to find as well as to validate the values of SFE $\left(\gamma_{\mathrm{S}}\right)$ those two method ware applied. Moreover, in OW method two sets of standard liquids (water-formamide and diiodometane-formamide) for the PU-PDMS surface investigation were used. The values of SFE and its components for applied standard liquids were summarized in Table 3.

\section{Persoz hardness}

The Persoz hardness of the PU-Si coatings on stainless steel pieces (dimensions of $100 \mathrm{~mm} \times 50 \mathrm{~mm} \times 1 \mathrm{~mm}$ ) was measured according to PN-EN ISO 1522:2001 standard in pendulum hardness tester (BYK-Gardner $\mathrm{GmbH}$, Germany). The Persoz hardness was obtained as the time of

Table 3 Surface free energy values of the model standard liquids for

\begin{tabular}{|c|c|c|c|c|c|c|c|c|}
\hline \multirow[t]{3}{*}{ Standard liquid } & \multicolumn{8}{|c|}{ Free surface energy parameters $/ \mathrm{mJ} \mathrm{m}^{-2}$} \\
\hline & \multicolumn{3}{|c|}{ Owens-Wendt model } & \multicolumn{5}{|c|}{ van Oss-Good model } \\
\hline & $\gamma_{\mathrm{L}}$ & $\gamma_{\mathrm{L}}^{\mathrm{d}}$ & $\gamma_{\mathrm{L}}^{\mathrm{P}}$ & $\gamma_{\mathrm{L}}$ & $\gamma_{\mathrm{L}}^{\mathrm{LW}}$ & $\gamma_{\mathrm{L}}^{\mathrm{AB}}$ & $\gamma_{\mathrm{L}}^{+}$ & $\gamma_{\mathrm{L}}^{-}$ \\
\hline Water & 72.8 & 21.8 & 51 & 72.8 & 21.8 & 51.0 & 25.5 & 25.5 \\
\hline Formamide & 58.0 & 39.0 & 19.0 & 58.0 & 39.0 & 19.0 & 2.28 & 39.6 \\
\hline Diiodomethane & 50.8 & 48.5 & 2.3 & 50.8 & 50.8 & 0 & 0 & 0 \\
\hline
\end{tabular}
OW and vOG models [23, 24] oscillations decay of the pendulum on material surface to glass constant. The values obtained were the average of three replicates.

\section{Results and discussion}

Structural analysis of PU-PDMS copolymers

The chemical structures of the PU-PDMS copolymers were verified on the basis of both IR as well as ${ }^{1} \mathrm{H}$ and ${ }^{13} \mathrm{C}$ NMR spectra.

Figure 2 shows the IR spectra of the PU-PDMS copolymers. An absence of NCO peak at 2,270 $\mathrm{cm}^{-1}$ indicates that the isocyanate conversion was complete. The characteristic absorption peaks which confirm formation of polyurethane can be found at around $3,323 \mathrm{~cm}^{-1}$ (-NH stretching), $1,700 \mathrm{~cm}^{-1}$ (-C=O stretching, first amide band), $1,530 \mathrm{~cm}^{-1}$ (-NH deformation, second amide band), and at $1,230 \mathrm{~cm}^{-1}$ (C-N stretching, third amide band). The build-in of the PDMS segments into the anionomer chains was confirmed by the presence of the strong $\mathrm{Si}-\mathrm{CH}_{3}$ band at $800 \mathrm{~cm}^{-1}$. $\mathrm{Si}-\mathrm{CH}_{3}$ deformation band at $1,257 \mathrm{~cm}^{-1}$ can be found only in the S1S sample with large siloxane content because in the others PU-PDMS that signal is covered with amide III band at $1,230 \mathrm{~cm}^{-1}$. Other characteristic IR bands present both in PU as well as PU-PDMS can be seen at around 1,035 and $1,097 \mathrm{~cm}^{-1}$ (-Si-O-Si- and/or $-\mathrm{C}-\mathrm{O}-\mathrm{C}-$ bending) and 2,795-2,968 $\mathrm{cm}^{-1}$ (C-H stretching).

Interpretation of ${ }^{1} \mathrm{H}$ and ${ }^{13} \mathrm{C}$ NMR spectra of all poly(urethane-siloxane) copolymer is presented in Table 4, where the protons and carbons signals were assigned to the particular structural parts of the polyurethane chain [25]. The numbers of particular atoms were provided in Fig. 1. The recorded NMR spectra fully confirmed the structure of the copolymers.

The formation of polyurethane was confirmed by the presence of chemical shift at $8.00 \mathrm{ppm}$ in ${ }^{1} \mathrm{H}$ NMR spectrum

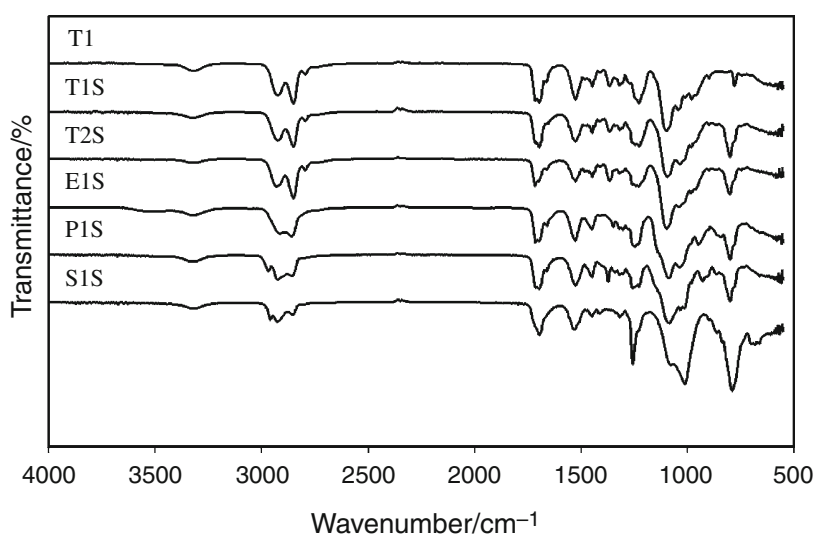

Fig. 2 FTIR spectra of poly(urethane-siloxane) copolymers 
and $155 \mathrm{ppm}$ in ${ }^{13} \mathrm{C}$ NMR spectrum which are attributed to proton 10 (-NHCOO-) and carbon 11 (-NHCOO-) in urethane bond respectively. There were no peaks at $124 \mathrm{ppm}$ characteristic for the $\mathrm{C}$ atom in an isocyanate group which confirms that diisocyanate was completely reacted. The same conclusion resulted also from the IR analysis. Two signals at $\delta \approx 0.07 \mathrm{ppm}\left({ }^{1} \mathrm{H} \mathrm{NMR}\right)$ and $\delta \approx 1.03 \mathrm{ppm}$ $\left({ }^{13} \mathrm{C} \mathrm{NMR}\right)$ assigned to corresponding atoms in methyl group in $\left(\mathbf{C H}_{3}\right)_{2}-\mathrm{SiO}$ which occur in all siloxane-modified samples confirm the build-in of PDMS into the polyurethane structure. In each synthesized polymer, there are structures derived from $\mathrm{H}_{12} \mathrm{MDI}$ and $\mathrm{BD}$ which can be found in NMR spectra. In ${ }^{1} \mathrm{H}$ NMR spectra the signals from $\mathrm{H}_{12} \mathrm{MDI}$ rings $(\mathbf{2}, \mathbf{3}, \mathbf{4})$ were present in the $0.96-1.25 \mathrm{ppm}$ range. Chemical shifts derived from BD occur at 1.56-1.68 ppm assigned to protons (7) in $-\mathrm{CH}_{2}-$ and at $4.06-4.19 \mathrm{ppm}$ assigned to protons (6) in $-\mathrm{CH}_{2}-\mathrm{OCONH}-$ group. The shifts for carbons in above-mentioned groups are also reflected in ${ }^{13} \mathrm{C}$ NMR spectra. Especially, the signals at $\delta=25.72-28.06$ and 70.61-75.37 ppm assigned to carbon (7) in $-\mathrm{CH}_{2}-$ and (6) in $-\mathrm{CH}_{2}-\mathrm{OCONH}-$ groups, respectively, which are derived from BD. The chemical shifts of particular atoms in different polyols used are assigned in detail and summarized in Table 4.
Molecular mass distribution

The results of GPC analysis comprising number average molecular mass $\left(\mathrm{M}_{\mathrm{n}}\right)$, mass average molecular mass $\left(M_{\mathrm{w}}\right)$, and polydispersity $\left(M_{\mathrm{w}} / M_{\mathrm{n}}\right)$ were presented in Table 5 . The largest molecular mass reveal unmodified PU sample T1. The polyurethane samples which were modified with sidechain siloxane resulted in lowering of this value (T1S). This may result from with poor segmental compatibility of nonpolar polydimethylsiloxane with hard segments and steric effect of side-chain siloxane $[14,26]$. The mass average molecular mass depends on polyol used and decrease in order: T2S $>$ P1S $>$ T1S $>$ S1S $>$ E1S. The largest molecular mass for sample $\mathrm{T} 2 \mathrm{~S}$ may be related to longer polyol segment (PTMO 2000) as well as lower amount of side-chain siloxane in its composition.

Thermal properties of PU-PDMS copolymers

\section{Thermal decomposition in nitrogen}

TG and DTG profiles for the PU-PDMS were presented in Figs. 3 and 4 whereas Table 6 provides interpretation of both profiles. On the TG curves, two basic degradation

Table 4 Interpretation of ${ }^{1} \mathrm{H}$ NMR and ${ }^{13} \mathrm{C}$ NMR spectra

\begin{tabular}{|c|c|c|c|c|c|c|c|c|c|c|c|c|}
\hline \multirow[t]{4}{*}{ Type of $\mathrm{H}$ or $\mathrm{C}$ nucleus (Fig. 1) } & \multicolumn{12}{|c|}{ Sample } \\
\hline & \multicolumn{2}{|l|}{$\mathrm{T} 1$} & \multicolumn{2}{|l|}{$\mathrm{T} 1 \mathrm{~S}$} & \multicolumn{2}{|l|}{$\mathrm{T} 2 \mathrm{~S}$} & \multicolumn{2}{|l|}{ E1S } & \multicolumn{2}{|l|}{ P1S } & \multicolumn{2}{|l|}{ S1S } \\
\hline & \multicolumn{12}{|c|}{ Chemical shift in NMR spectrum/ppm } \\
\hline & ${ }^{1} \mathrm{H}$ & ${ }^{13} \mathrm{C}$ & ${ }^{1} \mathrm{H}$ & ${ }^{13} \mathrm{C}$ & ${ }^{1} \mathrm{H}$ & ${ }^{13} \mathrm{C}$ & ${ }^{1} \mathrm{H}$ & ${ }^{13} \mathrm{C}$ & ${ }^{1} \mathrm{H}$ & ${ }^{13} \mathrm{C}$ & ${ }^{1} \mathrm{H}$ & ${ }^{13} \mathrm{C}$ \\
\hline 1 & 3.76 & 46.94 & 3.77 & 46.95 & 3.76 & 46.93 & 3.77 & 46.96 & 3.77 & 46.92 & 3.62 & 46.94 \\
\hline 2 & 1.10 & 32.04 & 1.10 & 32.05 & 1.10 & 32.04 & 1.10 & 32.02 & 1.10 & 32.05 & 1.10 & 32.02 \\
\hline 3 & 0.96 & 28.05 & 0.96 & 28.06 & 0.96 & 28.06 & 0.96 & 28.03 & 0.96 & 28.05 & 0.96 & 28.06 \\
\hline 4 & 1.25 & 29.70 & 1.25 & 29.70 & 1.25 & 29.71 & 1.25 & 29.70 & 1.23 & 29.71 & 1.25 & 29.71 \\
\hline 5 & 2.00 & 33.44 & 2.00 & 33.45 & 2.00 & 33.46 & 2.00 & 33.36 & 2.00 & 33.43 & 2.00 & 33.38 \\
\hline 6 & 4.06 & 70.61 & 4.06 & 70.62 & 4.06 & 70.61 & 4.07 & 70.56 & 4.07 & 75.37 & 4.19 & 74.14 \\
\hline 7 & 1.62 & 26.51 & 1.62 & 26.51 & 1.62 & 26.51 & 1.56 & 25.72 & 1.56 & 25.72 & 1.56 & 25.74 \\
\hline 8 & - & - & 0.51 & - & 0.51 & - & 0.51 & - & 0.51 & - & 0.52 & 14.06 \\
\hline 9 & - & - & 0.07 & 1.03 & 0.07 & 1.02 & 0.07 & 1.03 & 0.07 & 1.03 & 0.07 & 1.04 \\
\hline 10 & 8.03 & - & 8.04 & - & 8.02 & - & 8.09 & - & 8.06 & - & 8.06 & - \\
\hline 11 & - & 155.94 & - & 155.94 & - & 155.93 & - & 155.60 & - & 155.85 & - & 155.62 \\
\hline 12 & 3.41 & 70.61 & 3.41 & 70.62 & 3.41 & 70.61 & - & - & - & - & - & - \\
\hline 13 & 1.62 & 25.91 & 1.62 & 25.92 & 1.62 & 25.92 & - & - & - & - & - & - \\
\hline 14 & - & - & - & - & - & - & 4.19 & 70.56 & - & - & - & - \\
\hline 15 & - & - & - & - & - & - & 3.64 & 69.68 & - & - & - & - \\
\hline 16 & - & - & - & - & - & - & - & - & 3.55 & 75.36 & - & - \\
\hline 17 & - & - & - & - & - & - & - & - & 3.40 & 73.36 & - & - \\
\hline 18 & - & - & - & - & - & - & - & - & 3.14 & 17.32 & - & - \\
\hline 19 & - & - & - & - & - & - & - & - & - & - & 3.62 & 69.04 \\
\hline 20 & - & - & - & - & - & - & - & - & - & - & 4.19 & 74.14 \\
\hline
\end{tabular}


Table 5 Molecular masses of PU-PDMS copolymers

\begin{tabular}{lccc}
\hline Sample & $M_{\mathrm{n}} / \mathrm{g} \mathrm{mol}^{-1}$ & $M_{\mathrm{w}} / \mathrm{g} \mathrm{mol}^{-1}$ & $M_{\mathrm{w}} / M_{\mathrm{n}}$ \\
\hline T1 & 29,076 & 214,433 & 7.37 \\
T1S & 12,098 & 21,788 & 1.80 \\
T2S & 20,465 & 35,753 & 1.75 \\
E1S & 8,300 & 12,024 & 1.45 \\
P1S & 14,024 & 25,332 & 1.81 \\
S1S & 8,682 & 15,296 & 1.76 \\
\hline
\end{tabular}

stages can be distinguished. However, the DTG profiles reveal basically two main peaks but also additionally shoulder peak at the beginning of decomposition. That may suggest that the first degradation stage may comprise a few processes (parallel reaction, subsequent reactions or "overlapping" reactions, and possibly evaporation of remaining solvent which has been occluded) [27].

Decomposition of PU-PDMS, in terms of $5 \%$ mass loss $\left(T_{5} \%\right)$, takes place in the narrow temperature range of 284-288 ${ }^{\circ} \mathrm{C}$ for samples modified with S-PDMS containing PTMG 2000, PEG, PPG, or even S-PDMS soft segments. The beginning of the decomposition starts in the least thermal stable link which in polyurethanes is definitely urethane bond. Thus, the kind of soft segment does not strong influence $\mathrm{T}_{5} \%$. However, there is visible effect of S-PDMS modification on the increase in $5 \%$ mass loss temperature for the sample T1S in comparison to unmodified polyurethane (T1).

The mass loss at the first stage of degradation amounts to $23-52 \mathrm{wt} \%$ that corresponds to disintegration of rigid segments derived from $\mathrm{H}_{12} \mathrm{MDI}, \mathrm{BD}$, and S-PDMS. Temperature of maximum degradation rate at stage I $\left(T_{\max 1}\right)$ amounts to $322-357{ }^{\circ} \mathrm{C}$. Among the samples synthesized with PTMO, the largest $T_{\max 1}$ revealed the unmodified polyurethane T1. Introduction of $1.25 \mathrm{~mol} \%$ of S-PDMS to $\mathrm{T} 1$ sample resulted in slightly lowering of this value from 354.79 to $352.55{ }^{\circ} \mathrm{C}$. The siloxane-modified sample T2S composed of PTMO 2000 soft segments show lowest

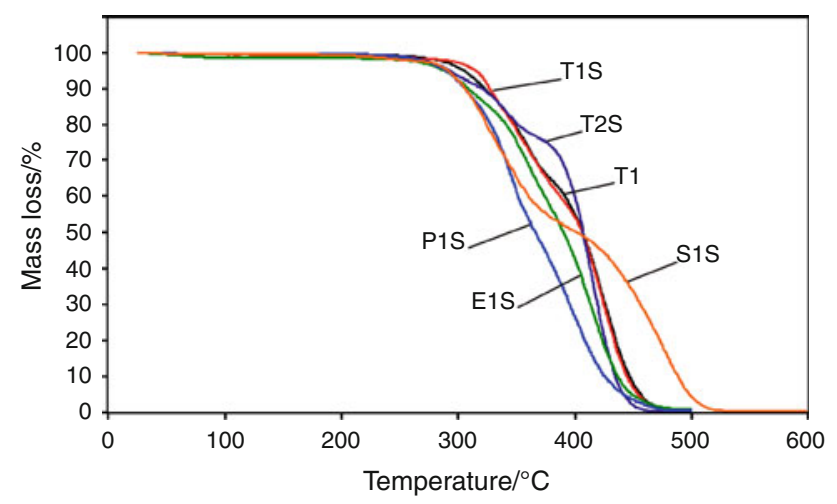

Fig. 3 TG curves of poly(urethane-siloxane), recorded in nitrogen

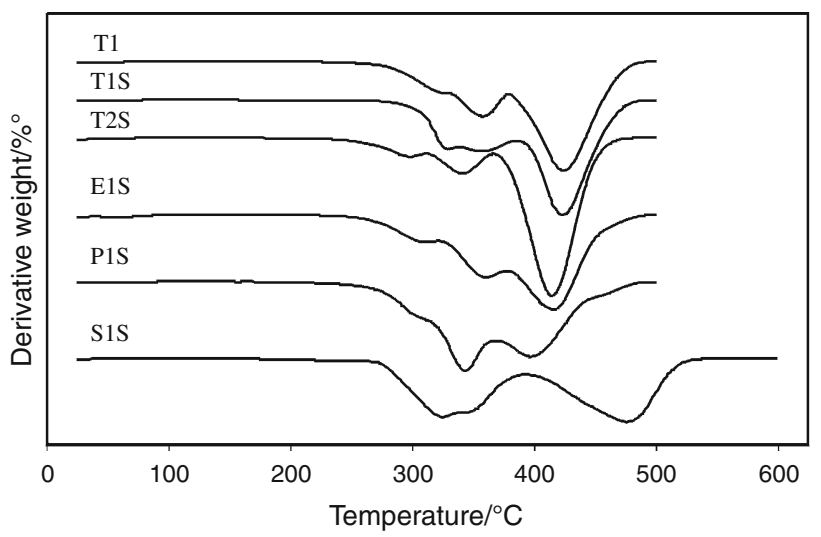

Fig. 4 DTG curves of poly(urethane-siloxane), recorded in nitrogen

$T_{\max 1}$ than the corresponding sample synthesized with PTMO 1000. This phenomenon can result from lower siloxane amount in the former sample. Among all the synthesized PU-PDMS the lowest $T_{\max 1}$ amounts to $322{ }^{\circ} \mathrm{C}$ revealed S1S sample indeed, but one should know that this peak is spited, which may influence on accuracy of this value. The mass loss at the second stage of degradation amounts to $47-76 \mathrm{wt} \%$ that corresponds to disintegration of soft segments derived from polyols [28, 29]. The maximal mass loss at this stage is observed for the T2S sample, where to soft segment content is the largest. Temperature of maximum degradation rate at stage II $\left(T_{\max 2}\right)$ amounts to $394-472{ }^{\circ} \mathrm{C}$. The largest $T_{\max 2}$ revealed S1S sample, where polydimethylosiloxane segments predominate.

Thermolytic decomposition ends at the temperature which is above $450{ }^{\circ} \mathrm{C}$ but for S1S sample which contain polydimethylsiloxane soft segments that temperature exceeds $530{ }^{\circ} \mathrm{C}$. The copolymers underwent nearly $100 \%$ decomposition. No solid residue found after degradation may confirm formation of volatile cyclic siloxane compounds.

\section{Thermal decomposition in air}

Thermal decomposition of PU-PDMS copolymers in air follows a more complex pattern. Figures 5 and 6 present TG and DTG curves, which were recorded for PU-PDMS at the heating rate of $10{ }^{\circ} \mathrm{C} \mathrm{min}^{-1}$, while Table 7 provides interpretation of TG and DTG profiles.

The $5 \%$ mass loss appears at $235-296{ }^{\circ} \mathrm{C}$ for all copolymers modified with S-PDMS and depends on soft segment used. For all samples, this temperature is generally lower in air than in nitrogen except for S1S. Moreover, the largest $T_{5} \%$ from all PU-PDMS revealed S1S sample which comprise large amount of siloxane structures. The temperature of $5 \%$ mass loss in side-chain siloxane-modified polyurethanes decreases in order: S1S $>$ T1S $>$ E1S $>$ T2S $>$ P1S. In contrast to nitrogen atmosphere, the modification of polyurethane with S-PDMS resulted in lowering $\mathrm{T}_{5} \%$ in air. 
Table 6 Decomposition temperature of PU-PDMS at $10{ }^{\circ} \mathrm{C} \min ^{-1}$ in nitrogen

\begin{tabular}{|c|c|c|c|c|c|c|c|}
\hline Sample & $T_{5} \% /{ }^{\circ} \mathrm{C}$ & $T_{50 \%}{ }^{\circ} \mathrm{C}$ & $T_{\max 1} /{ }^{\circ} \mathrm{C}$ & $\begin{array}{l}\text { Mass loss at stage } \\
\text { I of degradation/\% }\end{array}$ & $T_{\max 2} /{ }^{\circ} \mathrm{C}$ & $\begin{array}{l}\text { Mass loss at stage } \\
\text { II of degradation/\% }\end{array}$ & Residue at $500{ }^{\circ} \mathrm{C} / \%$ \\
\hline $\mathrm{T} 1$ & 301.04 & 403.57 & 354.79 & 35.5 & 421.09 & 64.1 & 0.4 \\
\hline T1S & 311.10 & 402.48 & 352.55 & 41.4 & 419.72 & 58.4 & 0.1 \\
\hline $\mathrm{T} 2 \mathrm{~S}$ & 288.87 & 403.82 & 338.14 & 23.8 & 411.53 & 76.1 & 0.1 \\
\hline E1S & 284.40 & 387.44 & 357.74 & 42.9 & 412.52 & 56.3 & 0.8 \\
\hline $\mathrm{P} 1 \mathrm{~S}$ & 286.13 & 363.43 & 340.72 & 52.2 & 394.42 & 47.5 & 0.3 \\
\hline S1S & 287.58 & 399.26 & 322.00 & 48.7 & 472.61 & 51.1 & $0.3^{*}$ \\
\hline
\end{tabular}

* For S1S residue at $600{ }^{\circ} \mathrm{C}$

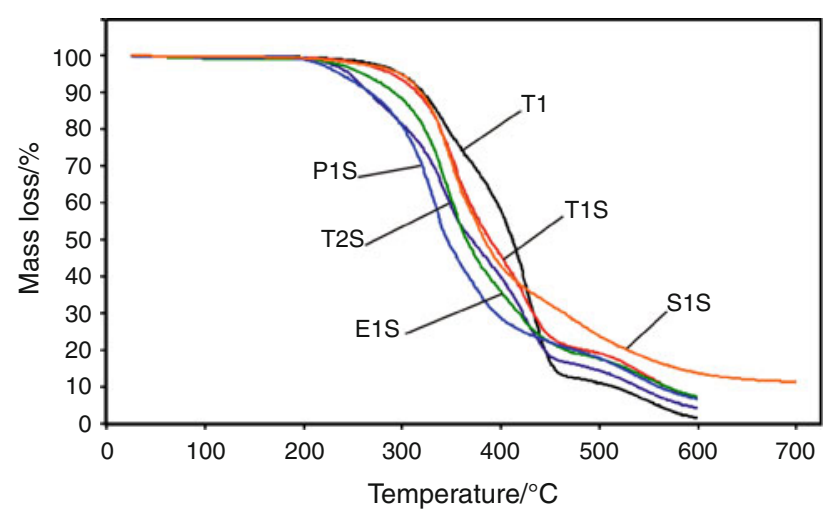

Fig. 5 TG curves of poly(urethane-siloxane), recorded in air

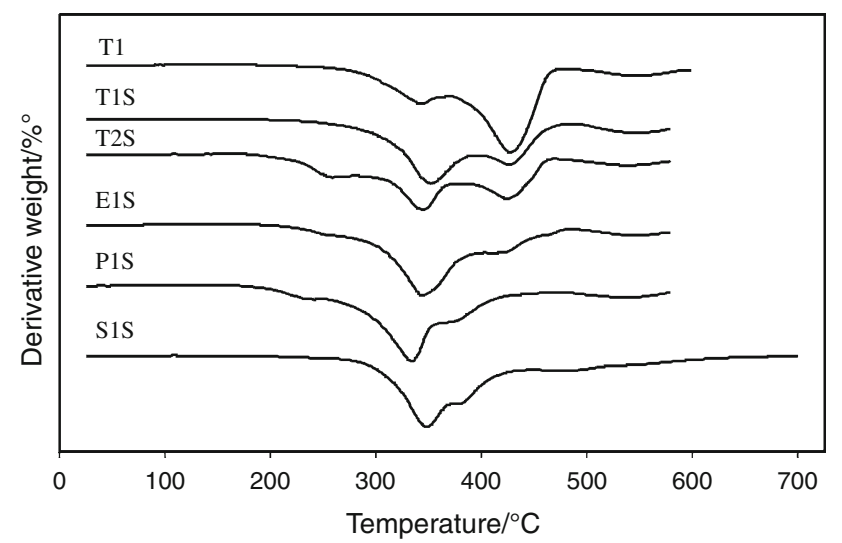

Fig. 6 DTG curves of poly(urethane-siloxane), recorded in air

The DTG profiles of the tested samples, for decomposition in air, demonstrate basically three maximum peaks for samples contained PTMO, which may suggest that the degradation process is composed of three stages. However, for the remaining samples only two main peaks can be distinguish because of the presence of shoulder peaks, which may additionally suggest more complex mechanism of degradation. Temperature of maximum degradation rate at stage I amounts to $332-350{ }^{\circ} \mathrm{C}$. The modification of polyurethane with S-PDMS resulted in increase $T_{\max 1}$. Among the PU-PDMS, the lowest $T_{\max 1}$ amounts to $332.64{ }^{\circ} \mathrm{C}$ revealed P1S sample containing poly(propylene glycol) soft segments.

The end of degradation temperature in air for the PU-PDMS studied is larger than in nitrogen and exceeds $550{ }^{\circ} \mathrm{C}$. The amount of solid residue after degradation for all modified samples at $600{ }^{\circ} \mathrm{C}$ was larger than for unmodified PU and exceeded $6.5 \%$. However, for the sample T2S where amount of siloxane was lower, this value amounts to $4.1 \%$. On the other hand, the largest residue $\left(11.1 \%\right.$ even at $\left.700{ }^{\circ} \mathrm{C}\right)$ was observed for S1S sample. Those findings seem to make the evidence for the formation of complex silicon-based structures in the pyrolysis process. The structures are formed on the surface and probably create the insulating layer which slows down further decomposition of the polymer, as it was observed for polyurethane-siloxane copolymers [30].

\section{Kinetic analysis of the decomposition process}

In order to study thermal degradation of PU-PDMS copolymers in detail, kinetic analysis of the observed thermal decomposition processes of those polymers in nitrogen was performed.

The general expression for the kinetic description of degradation of solids is [31]:

$\frac{\mathrm{d} \alpha}{\mathrm{d} t}=k(T) f(\alpha)$

where $\alpha$ is the conversion degree defined as the ratio of the actual mass loss to the total mass loss, $k(T)$ is the reaction rate constant, and $f(\alpha)$ is the kinetic model function. After substitution of the Arrhenius equation [32] and in nonisothermal conditions, when an expression responsible for the heating rate $\beta=\frac{\mathrm{d} T}{\mathrm{~d} t}$ is added to $(\mathbf{5})$, one arrives at:

$\frac{\mathrm{d} \alpha}{\mathrm{d} T}=\frac{A}{\beta} \exp \left(-\frac{E_{\mathrm{a}}}{R T}\right) \mathrm{d} \alpha$

where $A$-frequency factor, $E_{\mathrm{a}}$-activation energy, $R-$ universal gas constant, $T$-absolute temperature. 
Table 7 Decomposition temperature of PU-PDMS at $10{ }^{\circ} \mathrm{C} \mathrm{min}^{-1}$ in air

\begin{tabular}{|c|c|c|c|c|c|c|c|c|c|}
\hline Sample & $T_{5 \%} /{ }^{\circ} \mathrm{C}$ & $T_{50 \%} /{ }^{\circ} \mathrm{C}$ & $T_{\max 1} /{ }^{\circ} \mathrm{C}$ & $\begin{array}{l}\text { Mass loss at stage } \\
\text { I of degradation/\% }\end{array}$ & $T_{\max 2} /{ }^{\circ} \mathrm{C}$ & $\begin{array}{l}\text { Mass loss at stage } \\
\text { II of degradation } / \%\end{array}$ & $T_{\max 3} /{ }^{\circ} \mathrm{C}$ & $\begin{array}{l}\text { Mass loss at stage } \\
\text { III of degradation } / \%\end{array}$ & $\begin{array}{l}\text { Residue at } \\
600{ }^{\circ} \mathrm{C} / \%\end{array}$ \\
\hline $\mathrm{T} 1$ & 297.22 & 411.13 & 341.24 & 29.5 & 427.00 & 58.4 & 547.18 & 10.7 & 1.4 \\
\hline T1S & 287.56 & 388.35 & 350.93 & 52.8 & 424.14 & 27.5 & 543.86 & 13.2 & 6.6 \\
\hline $\mathrm{T} 2 \mathrm{~S}$ & 244.85 & 368.79 & 342.62 & 51.7 & 422.57 & 31.8 & 533.80 & 12.3 & 4.1 \\
\hline E1S & 258.46 & 364.26 & 342.79 & 81.5 & 543.48 & 11.4 & - & - & 7.2 \\
\hline P1S & 235.29 & 344.52 & 332.64 & 78.8 & 533.24 & 14.6 & - & - & 6.5 \\
\hline S1S & 296.09 & 382.78 & 346.36 & 66.6 & 474.84 & 22.3 & - & - & $11.1^{*}$ \\
\hline
\end{tabular}

* For S1S residue at $700{ }^{\circ} \mathrm{C}$

Two isoconversional methods by Ozawa-Flynn-Wall (OFW) [33, 34] and Friedman [35] were employed to evaluate of kinetic parameters in thermal decomposition of polymers under dynamic conditions in nitrogen. These methods may be used to determine and to monitor changes in the activation energy during the degradation process, without assumption of reaction model. Kinetic studies of solids with the use of isoconversional methods are extensively discussed in the literature [36-38]. The O-F-W method is based on the Doyle approximation [39], and it resolves itself to the use of the following equation:

$\ln \beta=\ln \left(\frac{A E_{\mathrm{a}}}{R}\right)-\ln g(\alpha)-5.3305+1.052 \frac{E_{\mathrm{a}}}{R T}$

In order to find the activation energy value $E_{\mathrm{a}}$ for a given degree of conversion $\alpha$, one should take a series of measurements for different heating rates $\beta$. Then, for a fixed degree of conversion ( $\alpha=$ const), straight lines are obtained in the diagram $\ln \beta=f(1 / T)$ for which the slope is defined as $m=1.052 \frac{E_{\mathrm{a}}}{R}$.

The Friedman isoconversional method [35] is based the following equation:

$\ln \frac{\mathrm{d} \alpha}{\mathrm{d} t}=\ln A+\ln f(\alpha)-\frac{E_{\mathrm{a}}}{R T}$

In order to find the activation energy value $E_{\mathrm{a}}$ for a given degree of conversion $\alpha$, one should take a series of measurements for different heating rates $\beta$. Then, for a fixed degree of conversion $(\alpha=$ const), straight lines are obtained in the diagram $\ln \left(\frac{\mathrm{d} \alpha}{\mathrm{d} t}\right)=f(1 / T)$ for which the slope is defined as $n=-\frac{E_{a}}{R}$.

Figures 7 and 8 illustrate the relationship between the activation energies $\left(E_{\mathrm{a}}\right)$ of the PU-PDMS and the degree of conversion by $\mathrm{O}-\mathrm{F}-\mathrm{W}$ and Friedman, respectively. The results obtained by both methods are similar. The presence of minimum at about $\alpha=0.25$ which may suggest that degradation that takes place in two steps is observed. For the T2S sample, this minimum is shifted toward lower $\alpha$ values, which results from lower hard segments content. This is because the hard

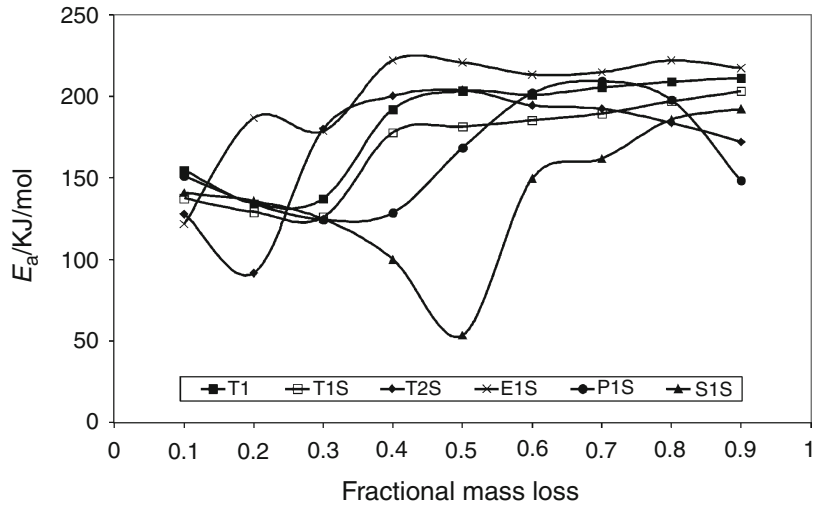

Fig. 7 Activation energy values calculated from the Friedman analysis of the degradation process of PU-PDMS copolymers

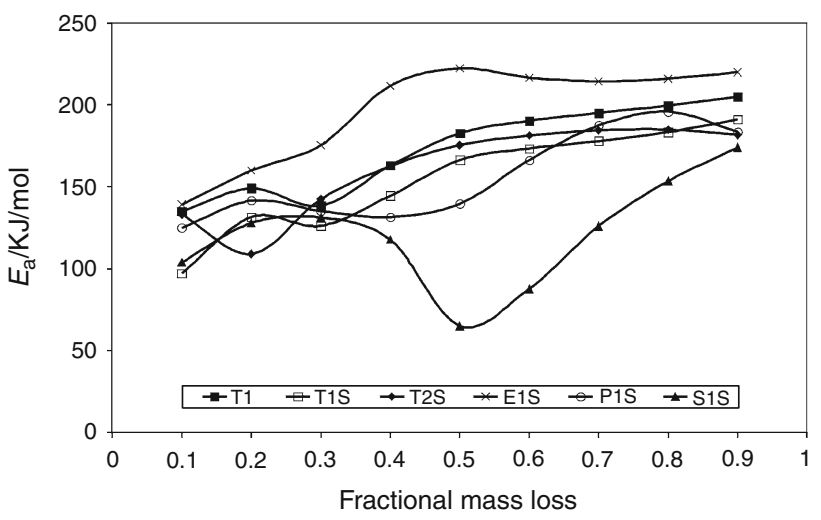

Fig. 8 Activation energy values calculated from the Ozawa-FlynnWall analysis of the degradation process of PU-PDMS copolymers

segments degrade at first step. The apparent activation energy at this step generally increases with the extent of conversion, which may result from complex mechanism of degradation at this stage related to formation of decomposition products and their diffusion through the solid sample. At the second stage of degradation, activation energy remains almost unaffected, which may be related to liquid polyol decomposition, where diffusion of volatile decomposition products is facilitated. The second stage of thermal degradation of S1S sample with PDMS 
Table 8 Roughness and Persoz hardness of PU-PDMS coatings

\begin{tabular}{llll}
\hline Sample & $R_{\mathrm{a}} / \mu \mathrm{m}$ & $R_{\mathrm{z}} / \mu \mathrm{m}$ & Persoz hardness \\
\hline T1 & 0.844 & 4.0 & 0.120 \\
T1S & 0.384 & 2.05 & 0.041 \\
T2S & 0.215 & 0.81 & 0.077 \\
E1S & 0.531 & 3.60 & 0.044 \\
P1S & 0.222 & 1.09 & 0.039 \\
S1S & 0.125 & 0.58 & 0.027 \\
\hline
\end{tabular}

soft segments is shifted to larger degree of conversion. Moreover, the apparent activation energy at this step increases with extent of degradation and is the lowest among all the copolymers. At this step, hydroxyl terminated PDMS is produced which then depolymerize, starting from chain ends, and forms volatile cyclic oligomers. This siloxane rearrangement via kinetically favored path requires much less activation energy as compared to the high siloxane $\mathrm{Si}-\mathrm{O}$ bond energy of $460.5 \mathrm{~kJ} \mathrm{~mol}^{-1}$ [40]. At higher temperature, radical mechanism of PDMS degradation occurs through homolytic $\mathrm{Si}-\mathrm{CH}_{3}$ bonds scission leading to cross-linking, which results in increase of activation energy [41].

Surface properties of the coatings obtained from PU-PDMS copolymers

\section{Roughness}

The surface of PU-PDMS films are smooth since the $R_{\mathrm{a}}$ and $R_{\mathrm{z}}$ values are very low as resulted from roughness data presented in Table 8. The largest $R_{\mathrm{a}}=0.844 \mu \mathrm{m}$ and $R_{\mathrm{z}}=4.0 \mu \mathrm{m}$ reveals unmodified sample $\mathrm{T} 1$. For the coatings containing siloxane both parameters are lower which may results from the migration of siloxane chains toward the film surface as described in [16]. This production of smoother surface may be additionally confirmed by the lowest $R_{\mathrm{a}}$ and $R_{\mathrm{z}}$ for S1S copolymer with the largest siloxane amount.

\section{Contact angle and FSE}

The contact angles for the coatings and the FSE components were presented in Table 9.

The least contact angles $\Theta$ were observed for the virgin polyurethane coating $\mathrm{T} 1$. The contact angles increase with the increasing polarity of the model liquids in order: diiodomethane, formamide, and water. The contact angles $\Theta$ for every model liquid in the poly(urethane-siloxane) case were larger than in the virgin polyurethane and were not affected by the kind of polyol used. This can be attributed to migration of pendant siloxane chain to the surface of coatings.

Similar trend is observed for the FSE results. The PU-PDMS coatings are generally slightly polar materials with the FSE in the range $14.7-21.1 \mathrm{~mJ} \mathrm{~m}^{-2}$. On the total, FSE mainly influence $\gamma_{\mathrm{S}}^{\mathrm{LW}}$ compound related to long-range interactions in van Oss-Good method. In case of method by Owens-Wendt, the contribution of $\gamma_{S}^{\mathrm{d}}$ compound related to dispersion interactions is significant. The maximal value of FSE $\left(28.9 \mathrm{~mJ} \mathrm{~m}^{-2}\right)$ reveals the virgin polyurethane sample. Introduction of $1.25 \mathrm{~mol} \%$ of S-PDMS results in lowering this value to $17.6 \mathrm{~mJ} \mathrm{~m}^{-2}$ (T1S), which additionally confirms hydrophobic character of siloxane used. The amount of S-PDMS in the coating made from T2S is lower $(5.2 \mathrm{wt} \%)$ than in corresponding $\mathrm{T} 1 \mathrm{~S}(8.0 \mathrm{wt} \%)$ which results in larger FSE $\left(18.7 \mathrm{~mJ} \mathrm{~m}^{-2}\right)$ for the former. For comparison, the FSE found in previous study of polyurethane synthesized with MDI, PTMO 1000, and BD but with about $5.5 \mathrm{wt} \%$ of linear L-PDMS modification was larger and amounted to $28.3 \mathrm{~mJ} \mathrm{~m}^{-2}$ [42]. The FSE of PU-PDMS depends on polyol used. The lowest value of FSE as expected revealed S1S sample, where additional siloxane structures were derived from soft segments participate in lowering of FSE due to migration to polymer surface. Among side-chain polysiloxane-modified PUPDMS the largest FSE reveals E1S sample, which results from contribution of polar PEG.

Table 9 Experimental values of the contact angles and the FSE parameters calculated by van Oss-Good and Owens-Wendt methods

\begin{tabular}{|c|c|c|c|c|c|c|c|c|c|c|c|c|c|c|}
\hline \multirow[t]{4}{*}{ Sample } & \multirow{3}{*}{\multicolumn{3}{|c|}{ Contact angle measurements $\Theta / \mathrm{deg}$}} & \multicolumn{11}{|c|}{ Parameters of the FSE $/ \mathrm{mJ} \mathrm{m}^{-2}$} \\
\hline & & & & \multirow{2}{*}{\multicolumn{5}{|c|}{ van Oss-Good method }} & \multicolumn{6}{|c|}{ Owens-Wendt method } \\
\hline & & & & & & & & & $\begin{array}{l}\text { Water } \\
\text { liquid }\end{array}$ & iiodo & thane & $\begin{array}{l}\text { Form } \\
\text { liquid }\end{array}$ & e-Di & nethane \\
\hline & Diiodomethane & Formamide & $\mathrm{H}_{2} \mathrm{O}$ & $\gamma_{\mathrm{S}}^{\mathrm{LW}}$ & $\gamma_{\mathrm{s}}^{+}$ & $\gamma_{\mathrm{s}}^{-}$ & $\gamma_{\mathrm{S}}^{\mathrm{AB}}$ & $\gamma_{\mathrm{S}}$ & $\gamma_{\mathrm{s}}^{\mathrm{d}}$ & $\gamma \stackrel{p}{s}$ & $\gamma_{\mathrm{s}}$ & $\gamma_{\mathrm{s}}^{\mathrm{d}}$ & $\gamma \stackrel{p}{\mathrm{p}}$ & $\gamma_{\mathrm{s}}$ \\
\hline $\mathrm{T} 1$ & $60.8 \pm 1.9$ & $74.0 \pm 1.3$ & $88.0 \pm 1.0$ & 28.1 & 0 & 6.5 & 0 & 28.1 & 24.9 & 4.0 & 28.9 & 27.0 & 1.1 & 28.1 \\
\hline $\mathrm{T} 1 \mathrm{~S}$ & $80.0 \pm 1.5$ & $90.4 \pm 2.3$ & $104.7 \pm 2.1$ & 17.5 & 0 & 2.0 & 0 & 17.5 & 16.2 & 1.4 & 17.6 & 17.0 & 0.5 & 17.5 \\
\hline $\mathrm{T} 2 \mathrm{~S}$ & $77.9 \pm 2.1$ & $88.7 \pm 1.7$ & $103.7 \pm 0.6$ & 18.6 & 0 & 2.0 & 0 & 18.6 & 17.3 & 1.4 & 18.7 & 18.2 & 0.5 & 18.7 \\
\hline E1S & $73.3 \pm 2.3$ & $82.4 \pm 1.9$ & $95.5 \pm 2.4$ & 21.1 & 0 & 4.5 & 0 & 21.1 & 18.6 & 3.2 & 21.8 & 19.7 & 1.4 & 21.1 \\
\hline P1S & $75.6 \pm 1.7$ & $88.6 \pm 2.2$ & $104.7 \pm 1.7$ & 19.8 & 0 & 1.6 & 0 & 19.8 & 18.9 & 0.9 & 19.8 & 19.9 & 0.2 & 20.1 \\
\hline S1S & $85.5 \pm 1.7$ & $94.7 \pm 2.4$ & $105.5 \pm 2.2$ & 14.7 & 0 & 3.0 & 0 & 14.7 & 13.2 & 1.8 & 15.0 & 14.3 & 0.5 & 14.8 \\
\hline
\end{tabular}




\section{Persoz hardness}

The Persoz hardness of the polyurethane coatings on stainless steel is presented in Table 8 . The obtained coatings are generally soft with the relative hardness in the range of $0.120-0.027$. The largest Persoz hardness reveals unmodified PU sample, which may result from higher cohesive forces in urethane segments leading to relatively denser physical cross-linking. The drop in hardness for all the coatings which were obtained from siloxane-modified samples was observed. The siloxane-modified sample T2S composed of PTMO 2000 soft segments show largest hardness than the corresponding sample synthesized with PTMO 1000 which may result from lower siloxane amount in T2S sample. The Persoz hardness values for the obtained PU-PDMS coatings are generally lower than for poly(urethane-siloxane) anionomers modified with side-chain siloxane for which this value amounts to ca. 0.245 [43].

\section{Conclusions}

A series of PU-PDMS containing different soft segment structures was successfully synthesized. It was concluded that molecular mass of PU-PDMS copolymers depend on polyol used. Thermal degradation of PU-PDMS in nitrogen is basically a two stage process, but, in air, it is more complex. The temperature of $5 \%$ mass loss in air for side-chain siloxanemodified polyurethanes decreases in order: S1S $>$ T1S $>$ E1S $>$ T2S $>$ P1S. In contrast to nitrogen atmosphere, the modification of polyurethane with S-PDMS resulted in lowering $T_{5} \%$ in air. The apparent activation energy at first step of degradation in nitrogen generally increases with the extent of conversion which may result from complex mechanism related to formation of decomposition products. At the second stage, $E_{\mathrm{a}}$ remains almost unaffected except S1S sample with PDMS soft segments. The PU-PDMS coatings are generally slightly polar materials with the FSE in the range $14.7-21.1 \mathrm{~mJ} \mathrm{~m}^{-2}$. Hydrophobic character of sidechain siloxane on surface properties of the PU-PDMS coatings was confirmed. Moreover, the FSE of the PU-PDMS depends on polyol used. The obtained coatings are generally soft with the relative hardness in the range of $0.120-0.027$. The largest Persoz hardness reveals unmodified PU sample, which may result from higher cohesive forces in urethane segments leading to relatively denser physical cross-linking than in siloxane-modified samples.

Open Access This article is distributed under the terms of the Creative Commons Attribution License which permits any use, distribution, and reproduction in any medium, provided the original author(s) and the source are credited.

\section{References}

1. Rabea MA, Mirabedini SM, Mohseni M. Investigating the surface properties of polyurethane based anti-graffiti coatings against UV exposure. J Appl Polym Sci. 2012;124:3082-91.

2. Choi SJ, Lee JH, Lee YH, Hwang DY, Kim HD. Synthesis and properties of polyurethane-urea-based liquid bandage materials. J Appl Polym Sci. 2011;121:3516-24.

3. Sommer SA, Byrom JR, Fischer HD, Bodkhe RB, Stafslien SJ, Daniels J, Yehle C, Webster DC. Effects of pigmentation on siloxane-polyurethane coatings and their performance as foulingrelease marine coatings. J Coat Technol Res. 2011;8(6):661-70.

4. Silvestri A, Serafini PM, Sartori S, Ferrando P, Boccafoschi F, Milione S, Conzatti L, Ciardelli G. Polyurethane-based biomaterials for shape-adjustable cardiovascular devices. J Appl Polym Sci. 2011;122:3661-71.

5. Król P, Byczyński Ł. Struktura, metody wytwarzania, właściwości i zastosowanie nowoczesnych kopolimerów poliuretanowo-polisiloksanowych. Przem Chem. 2007;86:643-51.

6. Osman AF, Edwards GA, Schiller TL, Andriani Y, Jack KS, Morrow IC, Halley PJ, Martin DJ. Structure-property relationships in biomedical thermoplastic polyurethane nanocomposites. Macromolecules. 2012;45:198-210.

7. Król P, Pielichowska K, Byczyński Ł. Thermal degradation kinetics of polyurethane-siloxane anionomers. Thermochim Acta. 2010;507-508:91-8.

8. Chuang FS, Tsi HY, Chow JD, Tsen WC, Shu YC, Jang SC. Thermal degradation of poly(siloxane-urethane) copolymers. Polym Degrad Stab. 2008;93:1753-61.

9. Pergal MV, Antic VV, Govedarica MN, Godevac D, Ostojic S, Djonlagic J. Synthesis and characterization of novel urethanesiloxane copolymers with a high content of PCL-PDMS-PCL segments. J Appl Polym Sci. 2011;122:2715-30.

10. Shia Z, Wang X. Preparation and characterization of polyurethanblock-poly(trifluoro- propylmethyl)siloxane elastomers. Polym Adv Technol. 2009;20:1017-23.

11. Zhang M, Wu Y, Wu H, Zhang Q, Xia Y. Synthesis and characterization of $\alpha, \omega$-bis(3-hydroxypropyl)-functionalized poly\{dimethylsiloxane-co-methyl[3-(2-acetyl-acetoxy)]propylsiloxane \}. J Appl Polym Sci 2012;125:595-607.

12. Choi T, Masser KA, Moore E, Weksler J, Padsalgikar A, Runt J. Segmented polyurethanes derived from novel siloxane-carbonate soft segments for biomedical applications. J Polym Sci Part B Polym Phys. 2011;49:865-72.

13. Wang J, Xia W, Liu K, Tuo X. Improved adhesion of silicone rubber to polyurethane by surface grafting. J Appl Polym Sci. 2011;121:1245-53.

14. Li CY, Chen JH, Chien PC, Chiu W, Chen RS, Don TM. Preparation of poly(IPDI-PTMO-siloxanes) and influence of siloxane structure on reactivity and mechanical properties. Polym Eng Sci. 2007; 47:625-32.

15. Zong J, Zhang Q, Sun H, Yu Y, Wang S, Liu Y. Characterization of polydimethylsiloxane-polyurethanes synthesized by graft or block copolymerizations. Polym Bull. 2010;65:477-93.

16. Chen RS, Chang CJ, Chang YH. Study on siloxane-modified polyurethane dispersions from various polydimethylsiloxanes. J Polym Sci Part A Polym Chem. 2005;43:3482-90.

17. Chen WH, Chen PC, Wang SC, Yeh JT, Yuan C-H, Chen KN. UV-curable PDMS-containing PU system for hydrophobic textile surface treatment. J Polym Res. 2009;16:601-10.

18. Stagg HE. A method for the determination of isocyanates. Analyst. 1946;71:557-9.

19. Zisman WA. Contact angle wettability and adhesion. Adv Chem Ser. 1964;43:1-51. 
20. Good JR In: Lee LH, editor. Fundamentals of adhesion. New York: Dekker; 1991

21. van Oss CJ, Chaudhury MK, Good RJ. Interfacial Lifshitz-van der Waals and polar interactions in macroscopic systems. Chem Rev. 1988;88:927-41.

22. Owens DK, Wendt RC. Estimation of the surface free energy of polymers. J Appl Polym Sci. 1969;13:1741-7.

23. Dann JR. Forces involved in the adhesive process: I. Critical surface tensions of polymeric solids as determined with polar liquids. Colloid Interf Sci 1970;32:302-20.

24. Żenkiewicz M. Modyfikowanie warstwy wierzchniej tworzyw wielkocząsteczkowych. Warszawa: WNT; 2000.

25. Pham, QT. Proton and carbon NMR spectra of polymers. 5th ed. Chichester, West Sussex, New York: Wiley; 2003.

26. Adhikari R, Gunatillake PA, McCarthy SJ, Meijis GF. Mixed macrodiol-based siloxane polyurethanes: effect of the comacrodiol structure on properties and morphology. J Appl Polym Sci. 2000;78:1071-82.

27. Pielichowski K, Pielichowski J, Prociak A. Chlorinated polyurethanes based on 2,4-toluenediisocyanate: thermal analysis and flammability evaluation. J Appl Polym Sci. 1998;67:1465-71.

28. Datta J, Balas A. DSC and thermal stability investigation of novel poly(ester-ether) glycols and poly (ester-ether)urethanes. J Therm Anal Calorim. 2003;74:615-21.

29. Datta J, Kacprzyk M. Thermal analysis and static strength of polyurethanes obtained from glycolysates. J Therm Anal Calorim. 2008;93:753-7.

30. Wang LF, Ji Q, Glass TE, Ward TC, McGrath JE, Muggli M, Burns G, Sorathia U. Synthesis and characterization of organosiloxane modified segmented polyether polyurethanes. Polymer. 2000;41:5083-93.

31. Šimon P. Isoconversional methods, fundamentals, meaning and application. J Therm Anal Calorim. 2004;76:123-32.

32. Arrhenius S. Uber die Reaktionsgeschwindigkeit bei der Inversion von Rohrzucker durch Säuren. Z Phys Chem. 1889;4:226.

33. Ozawa T. A new method of analyzing thermogravimetric data. Bull Chem Soc Japan. 1965;38:1881-6.
34. Flynn JH, Wall LA. A quick, direct method for the determination of activation energy from thermogravimetric data. J Polym Sci B Polym Lett. 1966;4:323-8.

35. Friedman HL. Kinetics of thermal degradation of char-forming plastics from thermogravimetry. Application to a phenolic plastic. J Polym Sci C Polym Symp 1964;6:183-95.

36. Farjas J, Roura P. Isoconversional analysis of solid state transformations, part I. Single step transformations with constant activation energy. J Therm Anal Calorim 2011;105:757-66.

37. Zabihi O, Omrani A, Rostami AA. Thermo-oxidative degradation kinetics and mechanism of the system epoxy nanocomposite reinforced with nano- $\mathrm{Al}_{2} \mathrm{O}_{3}$. J Therm Anal Calorim. 2012;108: 1251-60.

38. Albu P, Bolcu C, Vlase G, Doca N, Vlase T. Kinetics of degradation under non-isothermal conditions of a thermooxidative stabilized polyurethane. J Therm Anal Calorim. 2011;105:685-9.

39. Doyle CD. Estimating isothermal life from thermogravimetric data. J Appl Polym Sci. 1962;6:639-42.

40. Radhakrishan TS. New method for evaluation of kinetic parameters and mechanism of degradation from pyrolysis-GC studies: thermal degradation of polydimethylsiloxanes. J Appl Polym Sci. 1999;73:441-50.

41. Camino G, Lomakin SM, Lageard M. Thermal polydimethylsiloxane degradation. Part 2. The degradation mechanisms. Polymer. 2002;43:2011-5.

42. Król P, Byczyński Ł. Wpływ budowy chemicznej kopolimerów poli(uretanowo-siloksanowych) na wartości swobodnej energii powierzchniowej powłok $\mathrm{z}$ nich otrzymywanych. Polimery. 2008;11-12:808-16.

43. Byczyński $Ł$, Król P. Badania nad syntezą oraz właściwościami termicznymi i aplikacyjnymi anionomerów poli(uretanowodimetylosiloksanowych) Część II-Właściwości termiczne i aplikacyjne. Polimery 2013; in press. 